\title{
Dry powder alkali-activated slag cements
}

\author{
Maxim Kovtun \\ Researcher, Department of Civil Engineering, University of Pretoria, \\ Pretoria, South Africa \\ Elsabe P. Kearsley \\ Head of Department of Civil Engineering, University of Pretoria, Pretoria, \\ South Africa
}

\author{
Julia Shekhovtsova \\ PhD Student, Department of Civil Engineering, University of Pretoria, \\ Pretoria, South Africa
}

This paper reports on the results of an investigation into the possibility of producing dry powder alkali-activated slag cements as a ready-to-use product which can be packed in bags and mixed with water to produce a concrete. The cements were produced using a neutral granulated blast-furnace slag and sodium carbonate. To accelerate strength development at ambient temperatures, a combination of silica fume and slaked lime was used as accelerating admixture in the cement's formulation. Powder sodium lingosulfonate was added into the formulation to reduce the water demand of the cements; it also delayed setting and increased compressive strength. Alkali-activated slag concretes were produced using the developed cements. Compressive strengths in the range from 30 to $85 \mathrm{MPa}$ were achieved for the concretes at $\mathbf{2 8} \mathrm{d}$. The accelerating admixture increased 1-d compressive strength for the alkaliactivated slag concretes cured at ambient temperature up to $25 \mathrm{MPa}$. The optimum concentration of sodium carbonate was equivalent to $3 \cdot 5 \%$ and $4 \cdot 5 \%$ sodium oxide $\left(\mathrm{Na}_{2} \mathrm{O}\right)$ for precast and in situ application, respectively. The accelerating admixture is recommended at $6 \%$ for dry powder alkali-activated slag cements. The accelerated ageing test showed that the dry powder alkali-activated slag cement had a sufficient shelf life.

\section{Introduction}

Alkali activation of slag has been known for over 70 years (Purdon, 1940). Intensive research and development of alkaliactivated slag (AAS) cements and concretes has been carried out in the USSR by Glukhovsky and co-workers since the 1950s (Glukhovsky, 1959; Glukhovsky et al., 1983). During the last two decades AAS cements and concretes have been intensively studied worldwide (Bakharev et al., 1999a, 2000; Ben Haha et al., 2011; Collins and Sanjayan, 1999b; Douglas et al., 1991; Douglas and Brandstetr, 1990; Fernández-Jiménez et al., 1999; Wang et al., 1994, 1995; Živica, 2007). Interest in these cements is driven not only by the need of human society to reduce the carbon dioxide emissions, but also by several advantages that AAS cements can offer. These advantages include low heat of hydration, rapid hardening, high ultimate strength, resistance to chemical attack, heat resistance, low permeability, freeze-thaw performance and reduced sensitivity to aggregate quality (Bakharev et al., 2003; Shi and Stegemann, 2000; Shi, 1996; Wang et al., 1995; Xu et al., 2008). It is also known that AAS cements and concretes have several disadvantages, including fast setting, relatively high shrinkage (in comparison to ordinary Portland cement (OPC) concretes) and the formation of efflorescence (Atiş et al., 2009; Bakharev et al., 1999a, 1999b; Collins and Sanjayan, 1999a, 1999b; Živica, 2007). The resistance of AAS concretes to carbonation and alkali-silica reaction was questioned by Bakharev et al. (2001a, 2001b). Another disadvantage of AAS concretes is that they cannot be routinely used on construction sites, as the manufacturing process involves large volumes of alkaline liquids (Van Deventer et al., 2012). This is one of the key barriers to the widespread adoption of these materials.

There are four main activators usually used for alkali activation of slags, namely silicates $\left(\mathrm{M}_{2} \mathrm{O} \cdot n \mathrm{SiO}_{2}\right)$, hydroxide $(\mathrm{MOH})$, sulfate $\left(\mathrm{M}_{2} \mathrm{SO}_{4}\right)$ and carbonate $\left(\mathrm{M}_{2} \mathrm{CO}_{3}\right)$, where $\mathrm{M}$ is usually sodium or potassium (Wang et al., 1994). There are also three methods of adding the alkaline component to slag: in an aqueous solution, in the solid state by mixing dry alkali powder with slag or in the solid state where dry alkali powder is ground together with the slag (Moseson et al., 2012; Wang et al., 1994; Yang et al., 2008).

Dry powder AAS cements can be produced by grinding together a raw slag with an alkali and additives if necessary. Little research has been published on grinding slag with an alkali (Wang et al., 1994). However, producing a binder that can be used with the addition of water only will expand the use of AAS cements (Van Deventer et al., 2012).

Sodium silicate and sodium hydroxide or combinations of these two are usually the first choice for alkali activation of slags (Ben Haha et al., 2011; Douglas and Brandstetr, 1990; Douglas et al., 1991; Turner and Collins, 2013; Wang et al., 1994; Yang et al., 2008). Nevertheless, these alkalis are difficult to use in the production of dry powder AAS cements owing to the high hygroscopicity of sodium hydroxide and the poor solubility of 
sodium silicate, as well as the possible absorption of moisture by sodium silicate with silicate modulus (Ms) below 1.2 (Wang et al., 1994). A recent study by Turner and Collins (2013) also showed that the use of sodium hydroxide and silicate contributes significantly to the total carbon dioxide emissions associated with alkali-activated concrete production. In contrast to sodium hydroxide and sodium silicate, sodium carbonate is not hygroscopic, and the associated carbon dioxide emission is expected to be much lower (Moseson et al., 2012). The biggest disadvantage of using sodium carbonate in dry powder AAS cement is the slow strength development with neutral and acid slags at ambient temperatures (Wang et al., 1994). To overcome this problem, different accelerating admixtures can be used (Glukhovsky, 1959; Wang et al., 1994).

This paper reports on the results of an investigation into the possibility of producing dry powder AAS cements as a ready-touse product which can be packed in bags and mixed with water to produce a concrete. Eliminating the need for an alkaline solution gives the following advantages over traditional AAS concrete technology, where an alkali is introduced to the concrete mixture in the form of an aqueous solution.

- Safety on the construction site: aqueous solutions of alkalis used for activation are normally highly corrosive mediums and utilising them is hazardous.

- No need for a 'two packages' product.

- Quality control: in the case of an aqueous activator solution, two parameters should be controlled in the production process - the amount of liquid activator and its density (concentration). Technologically it becomes even more difficult to control AAS concrete mix design when aggregates are piled in open areas. Water from aggregates will dilute the activator solution, deteriorating many characteristics of AAS concrete. Keeping in mind the limits of solubility of typical activators in water at certain temperatures, it is obvious that in some cases it would not be possible to achieve the correct mix proportions. These hurdles do not exist for dry powder AAS cement.

\section{Experimental procedures}

\section{Materials}

A granulated blast-furnace slag (GBFS) was used to produce AAS cements. The chemical composition of the slag is presented in Table 1 . The basicity coefficient $\left(K_{\mathrm{b}}=(\mathrm{CaO}+\mathrm{MgO}) /\left(\mathrm{SiO}_{2}+\right.\right.$ $\left.\mathrm{Al}_{2} \mathrm{O}_{3}\right)$ ), activity coefficient $\left(K_{\mathrm{a}}=\mathrm{Al}_{2} \mathrm{O}_{3} / \mathrm{SiO}_{2}\right)$, and quality coefficient $\left(K_{\mathrm{q}}=\left(\mathrm{CaO}+\mathrm{Al}_{2} \mathrm{O}_{3}+\mathrm{MgO}\right) /\left(\mathrm{SiO}_{2}+\mathrm{TiO}_{2}\right)\right)$ based on the chemical composition are $0 \cdot 92,0 \cdot 41$ and $1 \cdot 67$, respectively. X-ray diffraction (XRD) analysis shows that the slag is mostly amorphous matter, and that it contains minor amounts of gehlenite. The specific gravity of the slag was $2900 \mathrm{~kg} / \mathrm{m}^{3}$.

Sodium carbonate powder ( $99 \%$ purity) was used as an activator. A combination of silica fume and slaked lime was used as an accelerating admixture to promote the strength development of dry powder AAS cements at ambient temperatures. Slag was replaced by the admixture at 2, 6 and $10 \mathrm{wt} \%$. The chemical compositions of silica fume and slaked lime are presented in Table 1. Sodium lignosulfonate powder was used as a plasticiser.

Crushed dolomite stone and dolomite sand were used as aggregates. The specific gravity of the aggregates was $2860 \mathrm{~kg} / \mathrm{m}^{3}$. The coarse aggregate had a maximum size of $9.5 \mathrm{~mm}$. The fineness modulus of the sand was 3.86 with $9 \%$ passing the $75 \mu \mathrm{m}$ sieve.

\section{Preparation of dry powder AAS cements}

The dry powder AAS cements were produced by grinding together the slag with sodium carbonate, the accelerating admixture and plasticiser in a laboratory steel ball mill. Compositions of the cements produced are shown in Table 2. The duration of milling was $3 \mathrm{~h} 30 \mathrm{~min}$ and $4 \mathrm{~h} 30 \mathrm{~min}$ to produce dry powder AAS cements with Blaine finenesses in the region of $390 \mathrm{~m}^{2} / \mathrm{kg}$ and $430 \mathrm{~m}^{2} / \mathrm{kg}$, respectively. Fineness of the cements was measured with a Blaine apparatus according to BS EN 196-6:2010 (BSI, 2010). A Malvern Mastersizer 2000 apparatus was used to determine a particle size distribution of the dry powder AAS cements.

\section{Production of AAS concretes}

During the second stage of this research, AAS concretes were produced. The binder (slag + silica fume + slaked lime) content was kept constant of $500 \mathrm{~kg} / \mathrm{m}^{3}$. Thus, the total AAS cement content with activator concentrations of $3.5,4.0$ and $4.5 \%$ sodium oxide was 530,534 and $538 \mathrm{~kg} / \mathrm{m}^{3}$, respectively. The binder content was chosen based on the following factors.

- Good workability at low water/binder (W/B) ratio due to a substantial amount of AAS paste. Workability cannot be

\begin{tabular}{|c|c|c|c|c|c|c|c|c|c|c|}
\hline Material & $\begin{array}{l}\text { Silicon } \\
\text { dioxide } \\
\left(\mathrm{SiO}_{2}\right)\end{array}$ & $\begin{array}{c}\text { Titanium } \\
\text { dioxide } \\
\left(\mathrm{TiO}_{2}\right)\end{array}$ & $\begin{array}{l}\text { Aluminium } \\
\text { oxide } \\
\left(\mathrm{Al}_{2} \mathrm{O}_{3}\right)\end{array}$ & $\begin{array}{l}\text { Iron oxide } \\
\quad\left(\mathrm{Fe}_{2} \mathrm{O}_{3}\right)\end{array}$ & $\begin{array}{c}\text { Magnesium } \\
\text { oxide } \\
(\mathrm{MgO})\end{array}$ & $\begin{array}{l}\text { Calcium } \\
\text { oxide } \\
(\mathrm{CaO})\end{array}$ & $\begin{array}{l}\text { Sodium } \\
\text { oxide } \\
\left(\mathrm{Na}_{2} \mathrm{O}\right)\end{array}$ & $\begin{array}{l}\text { Potassium } \\
\text { oxide } \\
\left(\mathrm{K}_{2} \mathrm{O}\right)\end{array}$ & $\begin{array}{c}\text { Sulfur } \\
\text { trioxide } \\
\left(\mathrm{SO}_{3}\right)\end{array}$ & $\begin{array}{l}\text { Loss on } \\
\text { ignition } \\
\text { (LOI) }\end{array}$ \\
\hline Slag & $34 \cdot 87$ & 0.72 & $14 \cdot 38$ & 0.89 & 8.03 & $37 \cdot 05$ & $<0.01$ & 0.72 & 1.96 & 0.16 \\
\hline Silica fume & $84 \cdot 00$ & 0.03 & 0.75 & 1.96 & 1.08 & $2 \cdot 22$ & 0.17 & $3 \cdot 43$ & 0.09 & $5 \cdot 56$ \\
\hline Slaked lime & $4 \cdot 01$ & 0.03 & 0.37 & 0.36 & $1 \cdot 67$ & $67 \cdot 80$ & 0.00 & 0.08 & $0 \cdot 11$ & $25 \cdot 0$ \\
\hline
\end{tabular}

Table 1. Chemical composition of materials used 


\begin{tabular}{lrccc}
\hline Cement ID & \multicolumn{4}{c}{ Components: wt\% } \\
\cline { 2 - 5 } & Slag & $\begin{array}{c}\text { Silica } \\
\text { fume }\end{array}$ & $\begin{array}{c}\text { Slaked } \\
\text { lime }\end{array}$ & $\begin{array}{c}\text { Activator (sodium oxide } \\
\text { eq. of slag mass) }\end{array}$ \\
\hline SC35-390 & 100 & & $3 \cdot 5$ \\
SC40-390 & 100 & & & $4 \cdot 0$ \\
SC45-390 & 100 & & & $4 \cdot 5$ \\
SC35-430 & 100 & & & $3 \cdot 5$ \\
SC40-430 & 100 & & & $4 \cdot 0$ \\
SC45-430 & 100 & & & $4 \cdot 5$ \\
SF2-500 & 98 & 1 & 1 & $4 \cdot 5$ \\
SF6-590 & 94 & 3 & 3 & $4 \cdot 5$ \\
SF10-570 & 90 & 5 & 5 & $4 \cdot 5$ \\
SF6-610 & 94 & 3 & 3 & $4 \cdot 5$ \\
SF6L-620 & 94 & 3 & 3 & $4 \cdot 5$ \\
\hline
\end{tabular}

a AAS cement contains sodium lingosulfonate plasticiser at $1.5 \mathrm{wt} \%$ of slag mass.

Table 2. AAS cement compositions

increased simply by adding water because it will reduce the $\mathrm{pH}$ of the system due to the diluting effect and will significantly impair the technical properties of AAS concrete (Shi and Day, 1996; Shi and Li, 1989).

- Durability of AAS concretes increases with increased binder content (Bernal et al., 2011).

- Optimal compressive strength of AAS concretes is achieved at about $25 \%$ binder content by volume (Ravikumar et al., 2010).
The coarse to fine aggregate ratio of $65: 35$ was kept constant in all mixes. The W/B ratio was $0 \cdot 30$ or $0 \cdot 35$. Concrete mix designs are shown in Table 3.

The concrete preparation procedure consisted of the mixing of dry aggregates with dry powder AAS cement in a pan mixer, the addition of water and then further mixing until a homogeneous fresh concrete mix was produced. After workability testing, the fresh concrete was immediately placed in $100 \mathrm{~mm}$ plastic cube moulds and vibrated. Two initial curing regimes were used: $25^{\circ} \mathrm{C}$ at $>90 \%$ relative humidity and steaming at $85^{\circ} \mathrm{C}$. Steamed samples were pre-cured at $25^{\circ} \mathrm{C}$ for $2 \mathrm{~h}$ (which was found in previous research to have a positive effect on the properties of AAS concretes (Bakharev et al., 1999b)) and then placed into steam baths. The temperature was increased to $85^{\circ} \mathrm{C}$ at a rate of $10^{\circ} \mathrm{C} / \mathrm{h}$, with the total duration of steam curing of $16 \mathrm{~h}$. No gradual cooling was used, and samples were de-moulded immediately after steaming. After de-moulding, the samples were stored in a room at $25^{\circ} \mathrm{C}$ and $55 \%$ relative humidity up to the day of testing.

\section{Testing methods}

The AAS cements' setting times were measured according to BS EN 196-3:2005 (BSI, 2005) using a Vicat apparatus. The W/B ratio was kept constant at $0 \cdot 25$, as the procedure of a standard paste consistency normally used for OPC cements (BSI, 2005) would influence the sodium carbonate/water ratio in the AAS pastes, changing the ionic and anionic concentration of the liquid media (Shi and Day, 1996; Shi and Li, 1989). Scanning electron microscope (SEM) investigations of AAS cements were done with a Zeiss Ultra Plus SEM at $1 \mathrm{kV}$. Sticky carbon tape was submerged into the AAS cement; glued cement particles were

\begin{tabular}{|c|c|c|c|c|c|c|}
\hline \multirow[t]{2}{*}{ Concrete ID } & \multicolumn{5}{|c|}{ Components: $\mathrm{kg} / \mathrm{m}^{3}$} & \multirow{2}{*}{$\begin{array}{c}\text { Slump: } \\
\text { mm/ } \\
\text { Vebe: } \mathrm{s}\end{array}$} \\
\hline & Cement & Stone & Sand & Water & W/B ratio & \\
\hline SC35-390 & 530 & 1189 & 646 & 175 & 0.35 & $30 /-$ \\
\hline SC40-390 & 534 & 1186 & 645 & 175 & 0.35 & $30 /-$ \\
\hline SC 45-390 & 538 & 1182 & 643 & 175 & 0.35 & $35 /-$ \\
\hline SC45-390 aged & 538 & 1182 & 643 & 175 & 0.35 & $10 /-$ \\
\hline SC35-390 & 530 & 1235 & 672 & 150 & $0 \cdot 30$ & $-/ 6$ \\
\hline SC40-390 & 534 & 1232 & 670 & 150 & $0 \cdot 30$ & $-/ 7$ \\
\hline SC45-390 & 538 & 1229 & 668 & 150 & $0 \cdot 30$ & $-/ 5$ \\
\hline SC35-430 & 530 & 1235 & 672 & 150 & $0 \cdot 30$ & $-/ 13$ \\
\hline SC40-430 & 534 & 1232 & 670 & 150 & $0 \cdot 30$ & $-/ 11$ \\
\hline SC45-430 & 538 & 1229 & 668 & 150 & 0.30 & $-/ 10$ \\
\hline SF2-500 & 538 & 1181 & 641 & 175 & 0.35 & $-/ 16$ \\
\hline SF6-590 & 538 & 1178 & 639 & 175 & 0.35 & $-/ 18$ \\
\hline SF10-570 & 538 & 1168 & 634 & 175 & 0.35 & $-/ 17$ \\
\hline SF6-610 & 538 & 1178 & 639 & 175 & 0.35 & $-/ 18$ \\
\hline SF6L-620 & 538 & 1178 & 639 & 175 & 0.35 & $-/ 10$ \\
\hline
\end{tabular}

Table 3. AAS concrete mix designs and workability 
coated with carbon. Workability (slump, Vebe test) of AAS concrete mixes was tested following the standard procedure of BS EN 12350:2009 (BSI, 2009a). Concrete samples were tested for compressive strength using $100 \mathrm{~mm}$ cubes according to BS EN 12390-3:2009 (BSI, 2009b) at $1 \mathrm{~d}$ (2 d if strength at day 1 was not enough for samples to be de-moulded), $28 \mathrm{~d}$ and $91 \mathrm{~d}$.

To estimate the shelf life of dry powder AAS cements, the AAS cement SC45-390 was aged in an opened bag at $25^{\circ} \mathrm{C}$ and $99 \%$ humidity for 9 weeks after manufacturing. A detailed study of prehydration of the AAS cements was not the main aim of this research and a rather practical approach was used, ageing the AAS cement in a bag instead of a thin layer of a few millimetres (Whittaker et al., 2013), assuming that AAS cement would be stored in bags as OPC normally is. Cement generally would not be stored in such conditions, but $99 \%$ humidity was used to intensify the ageing process, thus evaluating the performance of the cement if it would be stored for a long time (to replicate a worst-case scenario). After ageing, the AAS cement was studied using SEM to determine any differences in particle morphology in comparison to the fresh AAS cement.

\section{Results and discussion}

\section{Fineness of AAS cements}

The fineness of the dry powder AAS cements varied, depending on milling time and the composition of the cements as indicated in Table 4. AAS cements containing only slag and sodium carbonate were divided into two groups, cements with Blaine fineness values of about $390 \mathrm{~m}^{2} / \mathrm{kg}$ and about $430 \mathrm{~m}^{2} / \mathrm{kg}$. Higher fineness values were found in AAS cements containing silica fume and slaked lime. This increase in fineness could be explained by the softness and high initial specific surface area of slaked lime and silica fume. The Blaine fineness of AAS cements containing silica fume and slaked lime varied between 504 and $624 \mathrm{~m}^{2} / \mathrm{kg}$ depending on milling time, amount of the admixture and presence of the plasticiser. The addition of sodium lignosulfonate resulted in an increase in specific surface area of AAS cement from 606 to $624 \mathrm{~m}^{2} / \mathrm{kg}$ (Table 4), but this change is not deemed to be significant.

\section{Setting times of AAS cements}

Setting times of the AAS cements are presented in Table 4. An increase in alkali content (from SC35-390 to SC45-390) and fineness (from SC45-390 to SC45-430 and from SF6-590 to SF6$610)$ shortens the initial setting time. The final setting time seems to be sensitive to fineness of the AAS cements, with significantly shorter final setting times recorded with an increase in fineness. The final setting is not significantly affected by alkali content, which correlates with the findings made by Živica (2007).

The addition of silica fume and slaked lime does not influence the initial setting time but delays final setting (SF6-590 compared to SC45-390, Table 4). The plasticiser not only decreases water demand of dry powder AAS cement (see the later section entitled 'Workability of AAS concretes') but also prolongs setting times (SF6-610 compared to SF6L-620, Table 4), which is in agreement with other work (Bakharev et al., 2000). It is well known that plasticisers act as retarders with OPC (Neville, 1995). Very often the influence of plasticisers on OPC setting times is seen as a negative effect and accelerators are used in some cases to shorten setting time (Neville, 1995). This side-effect of using plasticisers can, however, be very useful and important for producing dry powder AAS cements because setting times of these cements are critical due to possible fast setting, especially with increasing fineness (Wang et al., 1995).

Ageing of AAS cement SC45-390 significantly delays both initial and final setting times. The delay is most probably caused by the formation of a crust of hydration products (see next section) on slag particles, which act as a barrier between slag particles and water (activator solution, after dissolution of sodium carbonate contained in the AAS cements) decelerating hydration of the AAS cement.

\begin{tabular}{lccccccc}
\hline Cement ID & $\begin{array}{c}\text { Time of milling: } \\
\text { min }\end{array}$ & $\begin{array}{c}\text { Particle size range: } \\
\mu m\end{array}$ & $d_{10}: \mu m$ & $d_{50}: \mu m$ & $\begin{array}{c}\text { Blaine: } \\
\mathrm{m}^{2} / \mathrm{kg}\end{array}$ & $\begin{array}{c}\text { Initial set: } \\
\text { h:min }\end{array}$ & $\begin{array}{c}\text { Final set: } \\
\text { h:min }\end{array}$ \\
\hline SC35-390 & 210 & $0 \cdot 3-168$ & $2 \cdot 3$ & $20 \cdot 5$ & 372 & $1: 05$ & $2: 10$ \\
SC40-390 & 210 & $0 \cdot 3-168$ & $2 \cdot 4$ & $21 \cdot 7$ & 393 & - & - \\
SC45-390 & 210 & $0 \cdot 3-168$ & $2 \cdot 2$ & $21 \cdot 5$ & 387 & $0: 50$ & $2: 15$ \\
SC45-390 aged & 210 & $0 \cdot 3-168$ & $2 \cdot 2$ & $21 \cdot 5$ & 387 & $3: 10$ & $6: 35$ \\
SC35-430 & 270 & $0 \cdot 3-138$ & $1 \cdot 5$ & $17 \cdot 6$ & 435 & - & - \\
SC40-430 & 270 & $0 \cdot 4-138$ & $1 \cdot 9$ & $18 \cdot 4$ & 434 & - & - \\
SC45-430 & 270 & $0 \cdot 4-125$ & $1 \cdot 7$ & $17 \cdot 5$ & 435 & $0: 45$ & $1: 05$ \\
SF2-500 & 210 & $0 \cdot 4-138$ & $1 \cdot 8$ & $20 \cdot 1$ & 504 & $0: 50$ & $2: 00$ \\
SF6-590 & 210 & $0 \cdot 4-138$ & $1 \cdot 5$ & $19 \cdot 3$ & 589 & $0: 45$ & $2: 45$ \\
SF10-570 & 210 & $0 \cdot 4-168$ & $1 \cdot 5$ & $19 \cdot 9$ & 573 & $1: 00$ & $2: 55$ \\
SF6-610 & 270 & $0 \cdot 4-138$ & $1 \cdot 6$ & $19 \cdot 4$ & 606 & $0: 30$ & $1: 40$ \\
SF10L-620 & 270 & $0 \cdot 4-152$ & $1 \cdot 3$ & $17 \cdot 3$ & 624 & $3: 45$ & $8: 30$
\end{tabular}

Table 4. AAS cements fineness and setting times 


\section{SEM observation of AAS cements}

Figure 1 shows SEM images of the AAS cement containing the accelerating admixture (SF6-610). Silica fume particles and slaked lime crystals can be observed on the surface of a slag particle (Figure 1(a)). As can be seen, inter-grinding provides close contact between slag, slaked lime and silica fume particles, which is important for early and long-term hydration because the early hydration process of AAS cement occurs through nucleation and growth mechanisms (Hubler et al., 2011), whereas the long-term reaction may continue through partially solid-state mechan-isms (Wang and Scrivener, 1995). In both cases close contact between the particles should facilitate the hydration process. In Figure 1(b), more fine particles deposited on the slag surface can be seen. Some particles went through amorphisation induced by the milling process (Scian et al., 1991; Tang et al., 2012; Tromans and Meech, 2001). The amorphisation of the particle surface favours leaching (Tang et al., 2012) and enhances dissolution (Tromans and Meech, 2001), potentially increasing the hydraulic activity (Paya' et al., 1997; Scian et al., 1991) of the AAS cement.

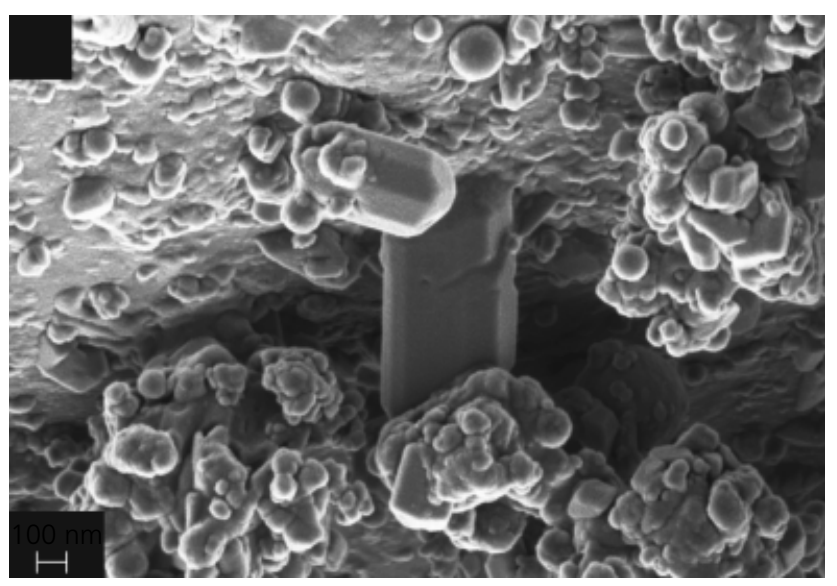

(a)

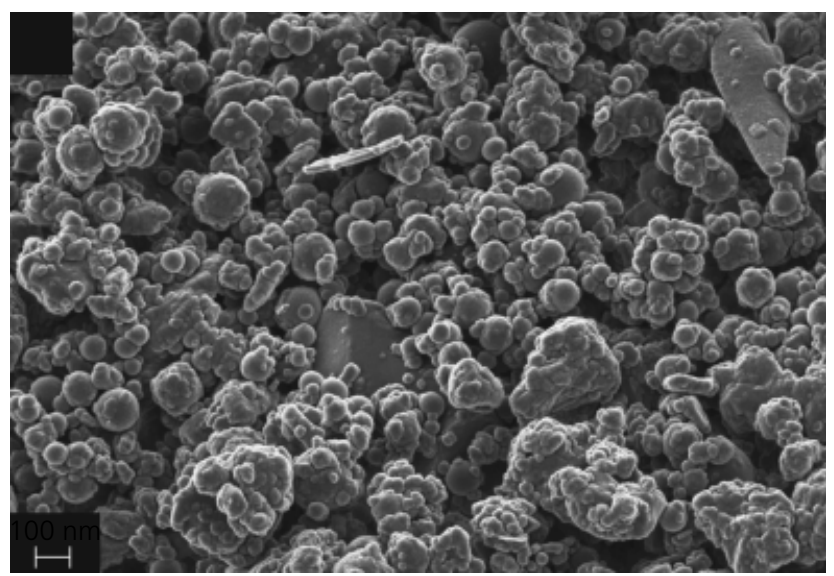

(b)

Figure 1. SEM images of AAS cement containing accelerating admixture of silica fume and slaked lime
Investigation of aged AAS cement with SEM showed that conglomerates of the cement particles were formed (Figure 2(a)), and some reaction, induced by water vapours in the fog room, took place (Figures 2(b)-2(d)). The fresh AAS cement does not form the conglomerates (Figure 3(a)) or large amounts of reaction products (Figure 3(b)) similar to that which cover particles of the aged AAS cement (Figures 2(c) and 2(d)). Similar formations of reaction products on the surface of prehydrated OPC particles were observed by Dubina et al. (2010) and Whittaker et al. (2013). These products effectively increase the surface area of the aged AAS cement and form a barrier between water and the unreacted part of the slag (Whittaker et al., 2013). The increased surface area increases the water demand of the cement, decreasing the workability of AAS concrete (see next section). The hydration products also result in rougher particle interlocking (Whittaker et al., 2013), contributing to the loss of the workability. The layer of hydration products could also be one of the reasons for decelerated hydration of aged AAS cement (Whittaker et al., 2013), which resulted in delayed setting times (Table 4).

\section{Workability of AAS concretes}

Workability of AAS concretes (as measured with Vebe and slump tests) was low, as indicated in Table 3. AAS concrete containing SC45-390 had a slump of $35 \mathrm{~mm}$, while workability of concrete containing aged SC45-390 cement was $10 \mathrm{~mm}$ slump. The reduction in workability could be caused by the increase in surface area of cement due to the formation of hydration products during the ageing process (Figure 2(d)) and the interlocking effect caused by increased roughness of the cement particles (Whittaker et al., 2013). AAS concretes containing SF6-610 and SF6L-620 cements had Vebe workability of 18 and $10 \mathrm{~s}$, respec-tively. Sodium lignosulfonate increased workability of the AAS concrete, indicating that water demand of the dry powder AAS cement SF6L-620 was reduced, which is critical in AAS concrete technology. The AAS concretes could be produced at lower W/B ratios. High W/B ratios impair strength development of AAS concretes by increasing porosity of the concretes due to the increase in water content (Wang et al., 1994). The increase in W/B ratio also changes the ionic and anionic concentration of the alkaline solution due to the effect of diluting (Shi and Day, 1996; Shi and Li, 1989) and, as a result, the $\mathrm{pH}$ of the solution decreases as the amount of alkali in the AAS cement is fixed. Reduced $\mathrm{pH}$ would significantly decelerate strength development of AAS cement at early age (Roy et al., 1992). It is even more critical for sodium carbonate as the initial $\mathrm{pH}$ of its aqueous solution is relatively low in comparison to most activators usually used in AAS concrete production. As a result of reduced $\mathrm{pH}$, initial hydration and early strength could be significantly impaired by the additional water introduced at high $\mathrm{W} /$ B ratios.

\section{Compressive strength}

Strength development of the dry powder AAS cements is sensitive to activator content, especially when AAS concretes are cured at ambient temperature. An increase in activator content from 3.5 t o $4 \cdot 5 \%$ sodium oxide results in a $47 \%$ increase in 


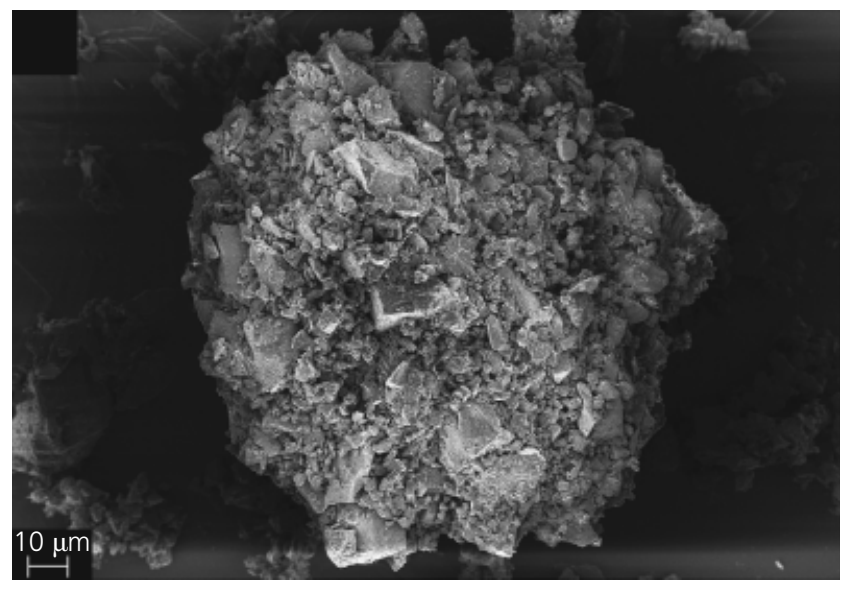

(a)

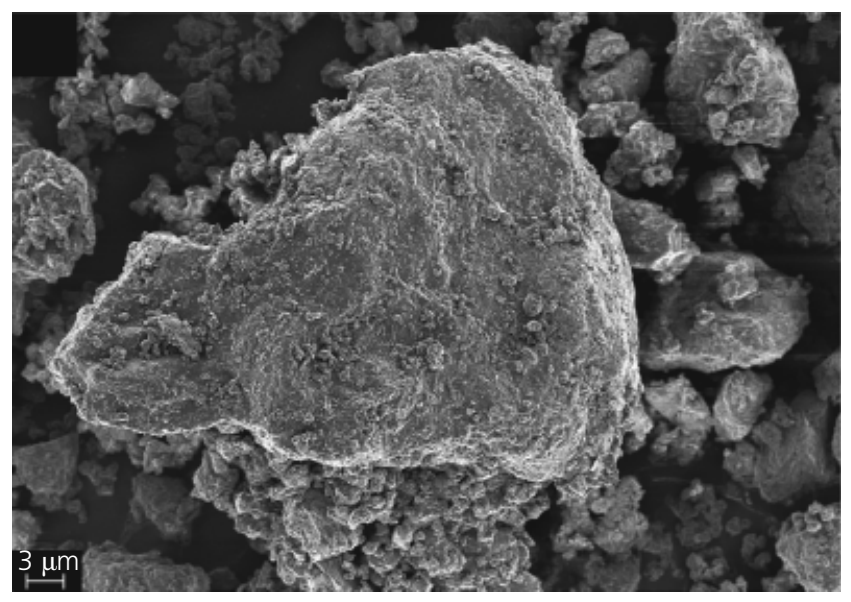

(c)

Figure 2. SEM images of aged AAS cement SC 45-390

compressive strength at $28 \mathrm{~d}$ from 29 to $42 \mathrm{MPa}$ (Figure 4). The sensitivity of the strength development to activator content is significantly reduced if AAS concretes are steamed. Only $16 \%$ difference in compressive strength at $28 \mathrm{~d}$ can be observed between AAS concretes containing 3.5 and $4.5 \%$ sodium oxide (Figure 4). The difference in strength drops even further to $14 \%$ when the W/B ratio is reduced from $0 \cdot 35$ to $0 \cdot 30$, and to $13 \%$ for cements with increased fineness (Figure 5).

Results presented in Figure 4 also show that the strength development of concretes containing the dry powder AAS cements, made from neutral GBFS and sodium carbonate, is slow at ambient temperature. Samples could not be demoulded after $1 \mathrm{~d}$ and strength testing was carried out after $2 \mathrm{~d}$, although hydration progresses with time, providing reasonable strengths at $28 \mathrm{~d}$ (Figure 4). Increased curing temperature significantly improves the performance of AAS concretes by accelerating strength development, especially at early age (Figures 4 and 5). Compressive strengths in the range from 57 to $65 \mathrm{MPa}$ were obtained at $28 \mathrm{~d}$ depending on the alkali concentration. More than 50\%

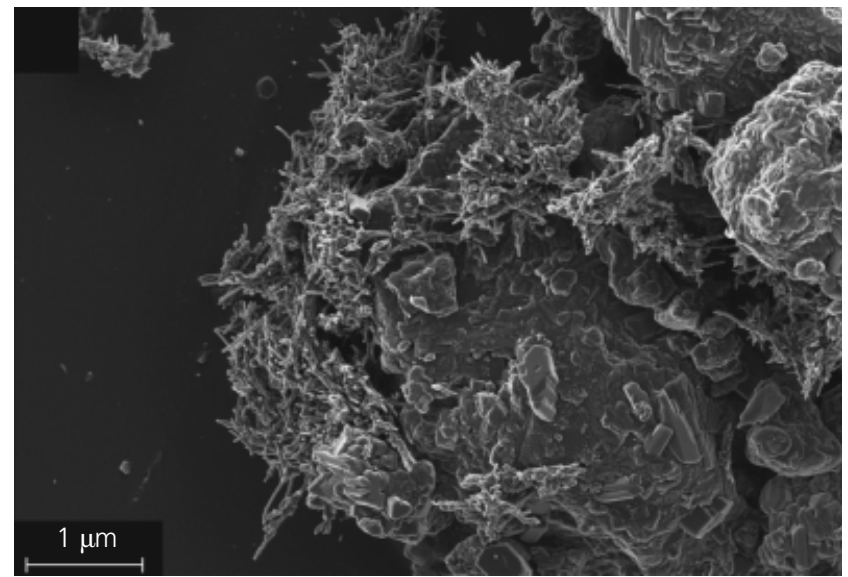

(b)

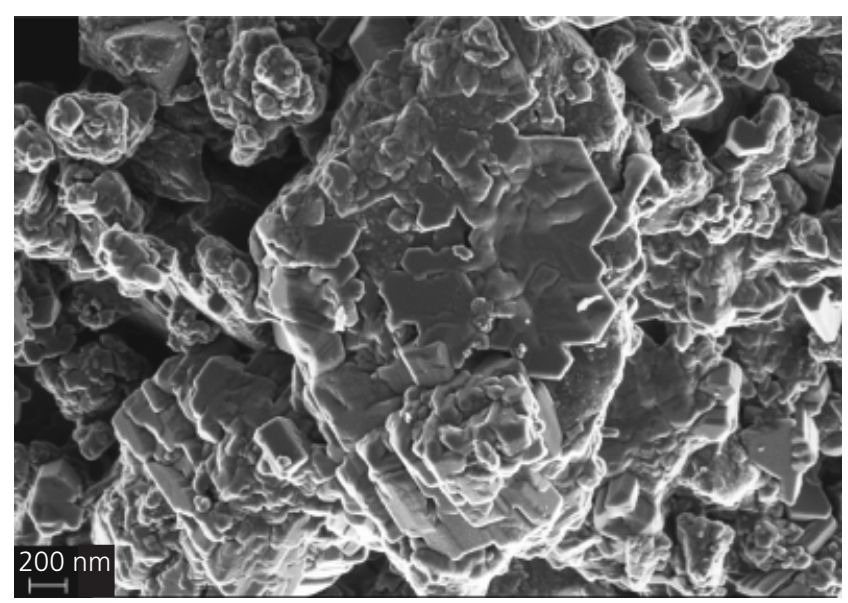

(d)

increase in strength can be achieved by steam curing of the AAS concretes (Figure 4). The high sensitivity of AAS concretes to heat treatment has also been reported by other researchers (Bakharev et al., 1999a, 1999b).

As mentioned above, it is interesting to note that the relative strength difference between concretes containing AAS cements with different concentration of sodium carbonate decreases significantly with heat treatment. The AAS cements are more sensitive to activator content when hardening at ambient temperatures. The best concentration of the activator in terms of compressive strength gained by AAS concrete will thus depend on the application of AAS cement; that is, the cements for precast production can be produced with lower activator content, which will reduce the cost of AAS cements and reduce the possibility of efflorescence formation on the surfaces of concrete products (Wang et al., 1995).

A reduction in water content leads to a significant increase in compressive strength of AAS concretes containing binders of the 


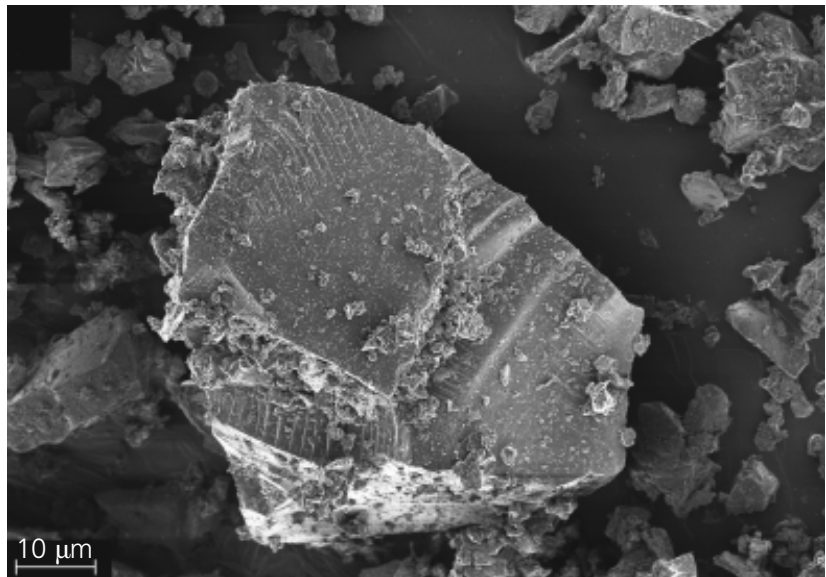

(a)

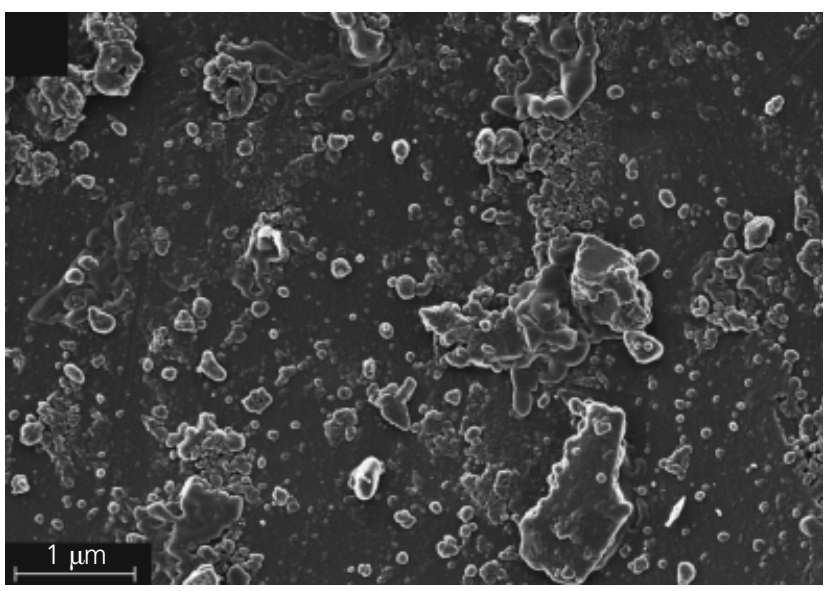

(b)

Figure 3. SEM images of fresh AAS cement SC45-390

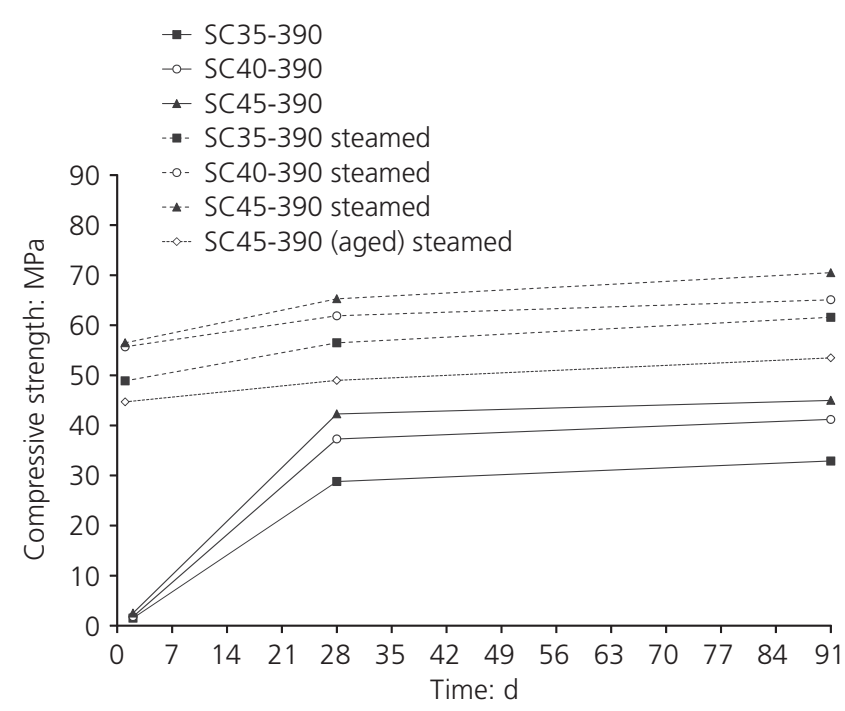

Figure 4. Strength development of AAS concretes with W/B ratio 0.35

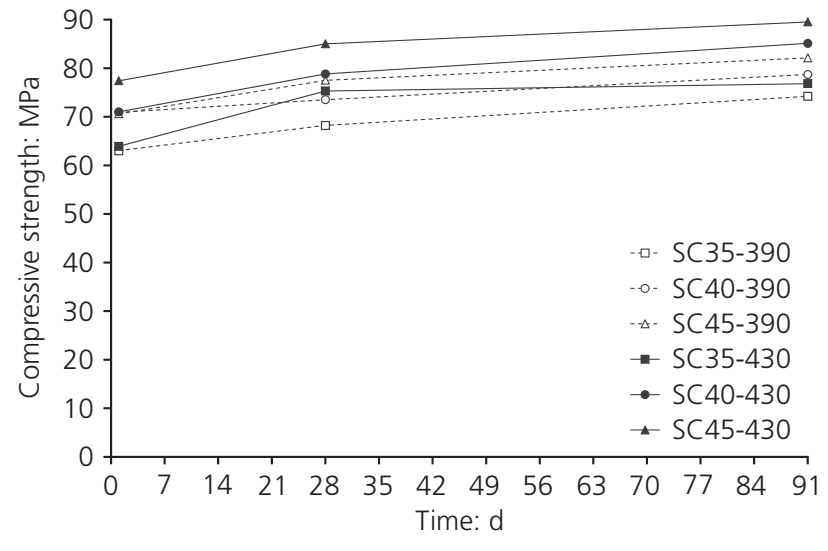

Figure 5. Strength development of AAS concretes with W/B ratio 0.30 steamed at $85^{\circ} \mathrm{C}$

390 series (Figure 5 compared to Figure 4); with more than 25\% strength increase immediately after steaming and about $20 \%$ at $28 \mathrm{~d}$. This is a big advantage of dry powder AAS cements over traditional AAS technology, where the alkali is introduced into the concrete mixture as an aqueous solution. The amount of alkaline solution cannot be reduced to a comparative extent because it will reduce the alkali concentration in AAS concrete due to a limit of sodium carbonate solubility in water at a certain temperature. This advantage increases the flexibility of AAS concretes containing dry powder AAS cements: the concretes can be designed to have the same strength properties with increased workability or to have higher strength performance with the same workability of fresh concrete mix, in comparison to traditional AAS concretes.

Increased fineness of dry powder AAS cement improved the compressive strength of AAS concretes by only $7-10 \%$ at $28 \mathrm{~d}$ (Figure 5). The increase is even less at $91 \mathrm{~d}$, varying between 0 and $9 \%$. AAS concretes containing SF3-590 and SF3-610 have almost no difference in compressive strength at 28 and $91 \mathrm{~d}$ (Figure 6), although initial strength at $1 \mathrm{~d}$ differs substantially. This confirms the findings of other researchers that increased fineness of slag mostly affects early-age compressive strength and does not necessarily improve the strength of AAS concretes in the long term (Shi and Li, 1989; Wang et al., 1994).

As shown in Figure 4, heat treatment is essential for strength development of AAS cements containing the neutral GBFS and sodium carbonate. Heat treatment very often cannot be done on a construction site. To accelerate hardening of dry powder AAS cements at ambient temperatures, a combination of silica fume with slaked lime was used (Figure 6). It can be seen that the optimum amount of the accelerating admixture was $6 \mathrm{wt} \%$. Although $2 \mathrm{wt} \%$ concentration of the admixture provides the highest strength in the long term, it does not accelerate strength development at early age sufficiently to be practical. In contrast $10 \mathrm{wt} \%$ concentration of combined silica fume and slaked lime 


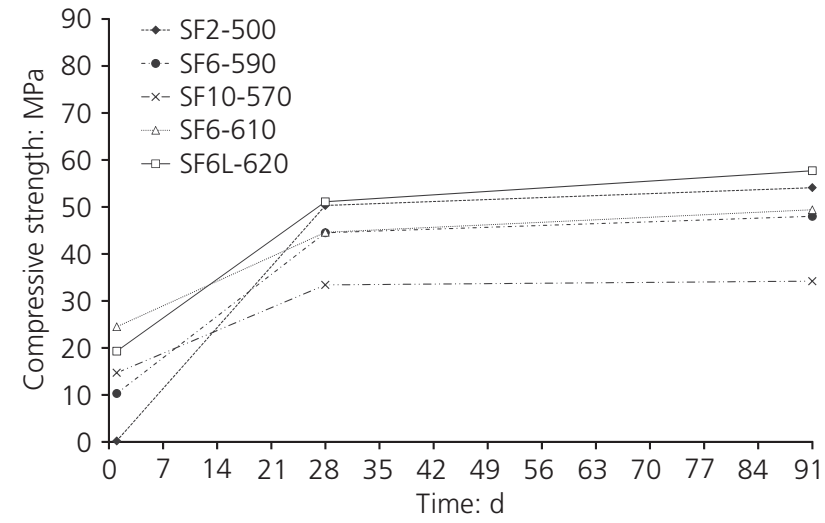

Figure 6. Strength development of AAS concretes with W/B ratio 0.35 at $25^{\circ} \mathrm{C}$ accelerated with combinations of silica fume and slaked lime

effectively accelerates strength development at early age but the long-term compressive strength is significantly impaired. As opposed to 2 and $10 \mathrm{wt} \%$ dosage, $6 \mathrm{wt} \%$ of the accelerating admixture gives a good balance between early and long-term compressive strength for AAS concretes (Figure 6). The compressive strength of AAS concretes increases from $2.5 \mathrm{MPa}$ at $2 \mathrm{~d}$ for SC45-390 to $10 \cdot 3 \mathrm{MPa}$ at $1 \mathrm{~d}$ for SF6-590 (Figure 4 compared to Figure 6). The effectiveness of the accelerating admixture goes up even more with increasing fineness of AAS cement, as illustrated by the fact that AAS concrete containing SF6-610 gained $24.5 \mathrm{MPa}$ in compressive strength in $1 \mathrm{~d}$ (Figure 6). Accelerated strength development can be explained by the increase in $\mathrm{pH}$ upon dissolution of the slaked lime and by calciumsilicate-hydrate $(\mathrm{C}-\mathrm{S}-\mathrm{H})$ formed during rapid reaction between silica fume and slaked lime. The calcium-silicate-hydrates act as crystallisation centres (substrate) for new portions of calciumsilicate-hydrate produced by the promoted slag hydration (Hubler et al., 2011; Shi and Day, 1996). The acceleration could also be explained by the reaction of slaked lime with sodium carbonate, resulting in the formation of sodium hydroxide that increases early-age compressive strength, but the reaction is not possible at $25^{\circ} \mathrm{C}$ (Gibbs energy is $55 \cdot 8 \mathrm{~kJ} / \mathrm{mol}$ ).

The addition of sodium lignosulfonate significantly increases the compressive strength of dry powder AAS cement with the accelerating admixture at the same W/B ratio (Figure 6). This phenomenon could be explained by the improved structure of the hydration product caused by a slower hydration process during the initial stage (Neville, 1995) and by a possible reaction between slag and the additional sodium brought into the system with the plasticiser.

After the ageing procedure, dry powder AAS cement SC45-390 was used to produce concrete with a compressive strength of $49 \mathrm{MPa}$ after $28 \mathrm{~d}$ (Figure 4) in comparison to the strength of AAS concrete containing fresh AAS cement SC45-390, which yielded $65 \mathrm{MPa}$ after $28 \mathrm{~d}$. Whittaker et al. (2013) showed that prehydration of OPC for only $28 \mathrm{~d}$ at $85 \%$ relative humidity caused around $13 \%$ loss in compressive strength of mortars at $28 \mathrm{~d}$. A loss of less than $25 \%$ in compressive strength during storage in extreme conditions ( $99 \%$ relative humidity) for 2 months could be a good indicator of sufficient shelf life for the dry powder AAS cements.

\section{Conclusions}

The following conclusions can be drawn from the results of this research.

- Sodium carbonate concentration in dry powder AAS cements can be varied depending on the cement application. The optimum concentration is $3 \cdot 5 \%$ sodium oxide for precast production with steam curing. For cast in situ application and curing at ambient temperatures, $4 \cdot 5 \%$ sodium oxide should be considered the optimum.

- Heat curing is essential for strength development of dry powder AAS cements containing neutral GBFS and sodium carbonate, but these cements can also be used for in situ applications where early strength is not critical.

- Combinations of silica fume and slaked lime accelerate strength development of dry powder AAS cements containing neutral GBFS and sodium carbonate to the extent that they can be used for in situ applications without special heat treatment on construction sites. For formulation of dry powder AAS cements, $6 \mathrm{wt} \%$ of the accelerating admixture can be recommended.

- The addition of sodium lignosulfonate not only reduces water demand, but also prolongs setting times and increases strength performance of dry powder AAS cements.

- Potentially, dry powder AAS cements have a sufficient shelf life, but long-term testing is required to confirm this.

- Further research is needed to estimate different engineering properties of AAS concretes containing dry powder AAS cement.

\section{Acknowledgements}

The authors would like to thank André Botha and Antoinette Buys of the Laboratory for Microscopy and Microanalysis of the University of Pretoria for their assistance in conducting the SEM studies.

\section{REFERENCES}

Atiş CD, Bilim C, Çelik Ö and Karahan O (2009) Influence of activator on the strength and drying shrinkage of alkaliactivated slag mortar. Construction and Building Materials 23(1): 548-555.

Bakharev T, Sanjayan JG and Cheng YB (1999a) Alkali activation of Australian slag cements. Cement and Concrete Research 29(1): 113-120.

Bakharev T, Sanjayan JG and Cheng YB (1999b) Effect of elevated temperature curing on properties of alkali-activated slag concrete. Cement and Concrete Research 29(10): 1619 1625. 
Bakharev T, Sanjayan JG and Cheng YB (2000) Effect of admixtures on properties of alkali-activated slag concrete. Cement and Concrete Research 30(9): 1367-1374.

Bakharev T, Sanjayan JG and Cheng YB (2001a) Resistance of alkali-activated slag concrete to alkali-aggregate reaction. Cement and Concrete Research 31(2): 331-334.

Bakharev T, Sanjayan JG and Cheng YB (2001b) Resistance of alkali-activated slag concrete to carbonation. Cement and Concrete Research 31(9): 1277-83.

Bakharev T, Sanjayan JG and Cheng YB (2003) Resistance of alkali-activated slag concrete to acidic attack. Cement and Concrete Research 33(10): 1607-1611.

Ben Haha M, Le Saout G, Winnefeld F and Lothenbach B (2011) Influence of activator type on hydration kinetics, hydrate assemblage and microstructural development of alkali activated blast-furnace slags. Cement and Concrete Research 41(3): 301-310.

Bernal SA, Gutierrez RM, Pedraza AL et al. (2011) Effect of binder content on the performance of alkali-activated slag concretes. Cement and Concrete Research 41(1): 1-8.

BSI (2005) BS EN 196-3: 2005. Methods of testing cement Part 3: Determination of setting times and soundness. BSI, London, UK.

BSI (2009a) BS EN 12350: 2009: Testing fresh concrete. BSI, London, UK.

BSI (2009b) BS EN 12390-3: 2009: Testing hardened concrete Part 3: Compressive strength of test specimens. BSI, London, UK.

BSI (2010) BS EN 196-6: 2010. Methods of testing cement Part 6: Determination of fineness. BSI, London, UK.

Collins F and Sanjayan JG (1999a) Strength and shrinkage properties of alkali-activated slag concrete containing porous coarse aggregate. Cement and Concrete Research 29(4): 607610.

Collins FG and Sanjayan JG (1999b) Workability and mechanical properties of alkali activated slag concrete. Cement and Concrete Research 29(3): 455-458.

Douglas E and Brandstetr J (1990) A preliminary study on the alkali activation of ground granulated blast-furnace slag. Cement and Concrete Research 20(5): 746-756.

Douglas E, Bilodeau A, Brandstetr J and Malhotra VM (1991) Alkali activated ground granulated blast furnace slag concrete: preliminary investigations. Cement and Concrete Research 21(1): 101-108.

Dubina E, Black L, Sieber R and Plank J (2010) Interaction of water vapour with anhydrous cement minerals. Advances in Applied Ceramics 109(5): 260-268.

Fernández-Jiménez A, Palomo JG and Puertas F (1999) Alkaliactivated slag mortars. Mechanical strength behavior. Cement and Concrete Research 29(8): 1313-1321.

Glukhovsky VD (1959) Soil-silicates. Gosstroiizdat, Kiev, USSR.

Glukhovsky VD, Krivenko PV, Rostovskaya GS, Timkovich VJ and Pankratov VL (1983) Binder. US Patent 4410365, Oct.

Hubler MH, Thomas JJ and Jennings HM (2011) Influence of nucleation seeding on the hydration kinetics and compressive strength of alkali activated slag paste. Cement and Concrete Research 41(8): 842-846.

Moseson AJ, Moseson DE and Barsoum MW (2012) High volume limestone alkali-activated cement developed by design of experiment. Cement and Concrete Composites 34(3): 328-336.

Neville AM (1995) Properties of Concrete, 4th edn. Longman, Harlow, UK.

Payá J, Monzó J, Borrachero MV, Peris E and González-López E (1997) Mechanical treatments of fly ashes. Part III: Studies on strength development of ground fly ashes (GFA) Cement mortars. Cement and Concrete Research 27(9): $1365-1377$.

Purdon AO (1940) The action of alkalis on blast furnace slag. Journal of the Society of Chemical Industry 59: 191-202.

Ravikumar D, Peethamparan S and Neithalath N (2010) Structure and strength of $\mathrm{NaOH}$ activated concretes containing fly ash or GGBFS as the sole binder. Cement and Concrete Composites 32(6): 399-410.

Roy A, Schilling PJ, Eaton HC et al. (1992) Activation of ground blast-furnace slag by alkali-metal and alkaline-earth hydroxides. Journal of the American Ceramic Society 75(12): 3233-3240.

Scian AN, Porto López JM and Pereira E (1991)

Mechanochemical activation of high alumina cements hydration behaviour. I. Cement and Concrete Research 21(1): $51-60$.

Shi C (1996) Strength, pore structure and permeability of alkaliactivated slag mortars. Cement and Concrete Research 26(12): 1789-1799.

Shi C and Day RL (1996) Some factors affecting early hydration of alkali-activated slag cements. Cement and Concrete Research 26(3): 439-447.

Shi C and Li Y (1989) Investigation on some factors affecting the characteristics of alkali-phosphorous slag cement. Cement and Concrete Research 19(4): 527-533.

Shi C and Stegemann JA (2000) Acid corrosion resistance of different cementing materials. Cement and Concrete Research 30(5): 803-808.

Tang A, Su L and Li C (2012) Effect of dry grinding on the physicochemical properties of silica materials prepared from kaolin residue. Powder Technology 218(March): 86-89.

Tromans D and Meech JA (2001) Enhanced dissolution of minerals: stored energy, amorphism and mechanical activation. Minerals Engineering 14(11): 1359-1377.

Turner LK and Collins FG (2013) Carbon dioxide equivalent $\left(\mathrm{CO}_{2}\right.$ e) emissions: a comparison between geopolymer and OPC cement concrete. Construction and Building Materials 43(June): 125-130.

Van Deventer JSJ, Provis JL and Duxson P (2012) Technical and commercial progress in the adoption of geopolymer cement. Minerals Engineering 29(March): 89-104.

Wang SD and Scrivener KL (1995) Hydration products of alkali activated slag cement. Cement and Concrete Research 25(3): 561-571.

Wang SD, Scrivener KL and Pratt PL (1994) Factors affecting the 
strength of alkali-activated slag. Cement and Concrete Research 24(6): 1033-1043.

Wang SD, Pu XC, Scrivener KL and Pratt PL (1995) Alkaliactivated slag cement and concrete: a review of properties and problems. Advances in Cement Research 7(27): 93-102, http://dx.doi.org/10.1680/adcr.1995.7.27.93.

Whittaker M, Dubina E, Al-Mutawa F et al. (2013) The effect of prehydration on the engineering properties of CEM I Portland cement. Advances in Cement Research 25(1): 12-20, http:// dx.doi/10.1680/adcr.12.00030.
Xu H, Provis JL, Van Deventer JSJ and Krivenko PV (2008) Characterization of aged slag concretes. ACI Materials Journal 105(2): 131-139.

Yang KH, Song JK, Ashour AF and Lee ET (2008) Properties of cementless mortars activated by sodium silicate. Construction and Building Materials 22(9): 1981-1989.

Živica V (2007) Effects of type and dosage of alkaline activator and temperature on the properties of alklali-activated slag mixtures. Construction and Building Materials 21(7): 14631469. 